\title{
Fear of cancer recurrence, anxiety and depressive symptoms in adolescent and young adult cancer patients
}

This article was published in the following Dove Press journal:

Neuropsychiatric Disease and Treatment

\author{
Hengwen Sun ${ }^{1, *}$ \\ Yuan Yang $2,3, *$ \\ Jingying Zhang ${ }^{3, *}$ \\ Ting Liu ${ }^{3, *}$ \\ Hongmei Wang ${ }^{4}$ \\ Samradhvi Garg ${ }^{5}$ \\ Bin Zhang ${ }^{3}$
}

'Department of Radiotherapy, Cancer Center, Guangdong Provincial People's Hospital (Guangdong Academy of Medical Sciences), Guangzhou 510080, People's Republic of China; 'Unit of Psychiatry, Faculty of Health Sciences, University of Macau, Macau SAR, Macau; ${ }^{3}$ Department of Psychiatry, Southern Medical University Nanfang Hospital, GuangdongHong Kong-Macao Greater Bay Area Center for Brian Science and BrainInspired Intelligence, Guangzhou, 5I05 I5, People's Republic of China; ${ }^{4}$ Department of Radiotherapy, Southern Medical University Nanfang Hospital, Guangzhou 5I05 I5, People's Republic of China;

${ }^{5}$ School of Health in Social Science, University of Edinburgh, Edinburgh EH8 9BL, UK

*These authors contributed equally to this work

Correspondence: Bin Zhang

Department of Psychiatry, Southern Medical University Nanfang Hospital,

No 1838 Guangzhoudadaobei

Guangzhou, Guangdong 510515, People's

Republic of China

$\mathrm{Tel} / \mathrm{Fax}+862061642066$

Email zhang73bin@hotmail.com
Background: Previous studies have indicated that younger age is consistently associated with high levels of fear of cancer recurrence (FCR), anxiety and depression. However, the associations among these variables in adolescent and young adult (AYA) cancer patients are not clear. This study explores the prevalence and correlates of FCR, anxiety and depressive symptoms in Chinese AYA cancer population.

Methods: This is a cross-sectional study that includes 249 patients aged between 15 and 39 yrs at the time of cancer diagnosis. Patient's sociodemographic, clinical as well as psychological characteristics were collected by an information sheet, the Fear of Progression Questionnaire-Short Form (FoP-Q-SF), General Anxiety Disorder Questionnaire (GAD-7) and Patient Health Questionnaire (PHQ-9). Descriptive statistics and multivariate analyses were conducted.

Results: Eighty-nine (35.74\%) patients experienced dysfunctional level of FCR, eighty-two (32.93\%) patients experienced anxiety symptoms and ninety-six (38.55\%) reported depressive symptoms. In multivariate analyses, being single, pessimistic, having more concurrent stressful life events and physical comorbidity were independently associated with higher FCR, anxiety and depressive symptoms. Patients who were not engaging in radiotherapy were more likely to report higher anxiety level.

Conclusion: FCR, anxiety and depressive symptoms are frequently reported problems among AYA cancer patients. Age-appropriate and flexible psychological interventions are needed for this high-risk population.

Keywords: adolescent, anxiety, cancer, depression, fear of recurrence, young adult

\section{Introduction}

Cancer is the leading cause for disease-related death among adolescent and young adult (AYA) cancer patients. ${ }^{1}$ It has been reported that about 70,000 AYA's are diagnosed with cancer every year in the United States, which represents nearly $6 \%$ of all new cancer diagnoses. $^{2}$ The definition of AYA is inconsistent among countries. In a recent report, the WHO summarizes that adolescents and youth are referred to as young people, encompassing the ages of 10-19 years. ${ }^{3}$ In the United Kingdom, researchers define the spectrum of AYAs as patients aged between 13 and 24 years. ${ }^{4}$ In the Netherlands, researchers define patients aged between 18 and 35 years at diagnosis as AYAs, while researchers in some other countries, such as China, have not yet set clear description of it. ${ }^{4}$ With no consistent utilization of age boundaries, age-specific research findings can be difficult to interpret. In 2009, the term "AYA" was defined as age 15-39 years by the National 
Cancer Institute, citing the lack of a health care niche and the lack of a "home" in medical research for this special group of population. $^{3}$

Previous studies have reported that $31-52 \%$ of cancer patients experienced fear of cancer recurrence (FCR), and $24-40 \%$ of them reported moderate to high levels of need for help in coping with it. ${ }^{5-7}$ FCR is defined as: fear, worry, or concern relating to the possibility that cancer will come back or progress. ${ }^{8}$ It was also described as fear of progression (FoP), ${ }^{9}$ or worry/concern about cancer relapse/return. ${ }^{10}$ Studies have consistently found that younger age at the time of cancer diagnosis, female gender, and patients with more physical symptoms/treatment side effects tend to experience more fears. ${ }^{5,11,12}$ Recent meta-analysis revealed that having received a mastectomy, ${ }^{13}$ radiation treatment ${ }^{14}$ as well as chemotherapy ${ }^{15}$ were significantly associated with greater FCR. However, most existing investigations of FCR have been performed with mixed-age cancer samples or adult samples of breast cancer patients. To our knowledge, no study has focused specifically on FCR in Chinese AYA population.

Emotional distress, such as anxiety, or depression, is considered as the sixth vital sign of a cancer patient's wellbeing along with signs of respiration, temperature, blood pressure, heart rate and pain. ${ }^{16}$ Emotional difficulties are common among cancer populations and compromise patients' quality of life, negatively affect treatment adherence and lead to a higher risk of mortality. ${ }^{17-19}$ A metaanalysis indicated that approximately $32 \%$ of cancer patients experience some type of psychological distress during active treatment, ${ }^{20}$ and emotional disturbance was inversely associated with age. ${ }^{21}$ In 2015, a review of 34 articles reported that all studies found a significant association between younger age and psychological distress during cancer trajectory. ${ }^{22}$ However, the limited number of AYA psycho-oncology studies has impeded these young patients' voices from being heard. Health care and survival in AYA age range has not shown any improvement in over two decades. ${ }^{22}$ In China, medicine and society are still largely unaware of the AYA oncology population.

AYA cancer patients have unique biological and psychological needs; ${ }^{23}$ we believe more attempts should be made to fill the gap between the pediatric and adult medical research to provide better insights into AYA cancer patients and their suffering. In this study, we concentrated on Chinese AYA patients aged between 15 and 39 years old at the time of cancer diagnosis and aim to assess the prevalence and correlates (sociodemographic, clinical and psychological) for FCR, anxiety and depressive symptoms.

\section{Methods}

\section{Participants and settings}

A consecutive sampling method was utilized to recruit participants from Guangdong Provincial People's Hospital (cancer center) and Southern Medical University Nanfang Hospital (department of oncology and radiotherapy) between 1 January 2018 and 30 November 2018. Inclusion criteria were patients: 1) who had a clear diagnosis of cancer; 2) aged between 15 and 39 years at the time of diagnosis; 3) and able to understand Mandarin or Cantonese. Exclusion criteria were patients: 1) blind/deaf; 2) have disturbance of consciousness; 3 ) receiving palliative treatment.

All patients were approached and recruited by a senior oncologist (HWS) and a trained research nurse (TL) through a scheduled outpatient consultation. A consultant psychiatrist (BZ) supervised the recruitment procedure. Participants were guaranteed that their participation would be kept confidential, and they could withdraw or discontinue participation at any time without giving any explanation. Approval was required from a parent/legal guardian for participants under the age of 18 years. The Southern Medical University Nanfang Hospital and Guangdong Provincial People's Hospital Research Ethics Committee examined and approved the study (ref No: NFEC-2018-038, and 2018295H(R1)).

\section{Measurements} Information sheet

A 14-item self-designed sheet was used to gather participants' demographic (4 items: age, gender, etc.), clinical (7 items: cancer type, stage, etc.) and psychological information (3 items; personality tendency, stressful life events, etc.). Patients' treatment history (radiotherapy, chemotherapy, surgery), physical comorbidity, family cancer history and past adversity experience (ie abuse, bullying, natural calamities, etc.) were assessed using "Yes/No" questions. Patients' personality tendency was measured by a single question derived from the Personality Traits Questionnaire, ${ }^{24}$ what do you think is your dominant personality trait (Positive or Negative)? The remaining questions were multiple choice questions.

\section{Fear of Progression Questionnaire-Short Form (FoP-Q-SF)}

The FoP-Q-SF is a 12-item questionnaire which has been frequently used to assess patient's FCR in several countries. $^{25-27}$ The items range from 1 to 5 ("never" to "very often"), and the resulting total score ranges from 
12 to 60 . The psychometric properties of the Chinese FoP-Q-SF have been examined by $\mathrm{Wu}$ et al. in 2015 (Cronbach's alpha $=0.883$ ), and it is the only validated FCR measurement in the Chinese language. ${ }^{28} \mathrm{~A}$ higher total score indicates higher FCR, and a score of 34 or above indicates a dysfunctional level of FCR. ${ }^{29}$ The Cronbach's alpha of FoP-Q-SF in this study was 0.848 .

\section{General Anxiety Disorder Questionnaire (GAD-7)}

The 7-item self-report GAD is a brief scale used to evaluate an individual's anxiety level. Response options are "not at all" (scores as 0 ), "several days" (scores as 1), "more than half the days" (scores as 2) and "nearly every day" (scores as 3 ). ${ }^{30}$ The Chinese GAD Cronbach's alpha was $0.91,{ }^{31}$ and a sum score of 5 or more indicated anxiety symptoms. The Cronbach's alpha for this current sample was 0.883 .

\section{Patient Health Questionnaire (PHQ-9)}

The 9-item self-report PHQ is developed as a screener for depression and has been commonly used in clinical settings. Its items range from 0 to 3 ("not at all" to "nearly everyday"), and a total score of 5 or more indicates depressive symptoms. ${ }^{32}$ The Chinese PHQ showed satisfactory psychometric properties (internal consistency $=0.89$ ),${ }^{33}$ and in this study, the Cronbach's alpha of the sample was 0.802 .

\section{Statistical analysis}

Data were analyzed with SPSS version 16. First, normal distribution assumption was examined. Difference in means was examined by a $t$-test for independent samples. Analysis of variance and the post hoc Bonferroni test were adopted to identify group effects. For continuous variables that were not normally distributed, Mann-Whitney U tests or Kruskal-Wallis tests (K-W tests) were conducted, as appropriate. The associations between score of FCR, anxiety and depression were examined by Pearson's correlation analysis if they were normally distributed, or Spearman's correlation was performed. Second, for factors which showed significant association with FCR, anxiety or depression in the above univariate analyses, their independent associations were further tested using multiple linear regression (dummy-coded variables were utilized). The statistical significance level was based on two-sided tests and was set at 0.05 .

\section{Results}

\section{Recruitment and data collection}

Patient recruitment flowchart is shown in Figure 1. In total, 966 cancer patients who were under active treatment were screened and 308 were found eligible. Of these patients, $55(17.86 \%)$ refused to take part in the study, and $253(82.14 \%)$ signed the written informed consent form. The major reasons for refusal were: too busy (47.27\%), and not interested in the study (41.82\%). Of the 253 patients, $249(98.42 \%)$ completed all assessments and eventually formed the study sample used.

\section{Patient characteristics}

The mean age of patients was 33.12 years $(\mathrm{SD}=4.82)$, ranging from 17 to 39 . Most of the participants were female $(68.3 \%)$, married $(73.5 \%)$ and with full-time

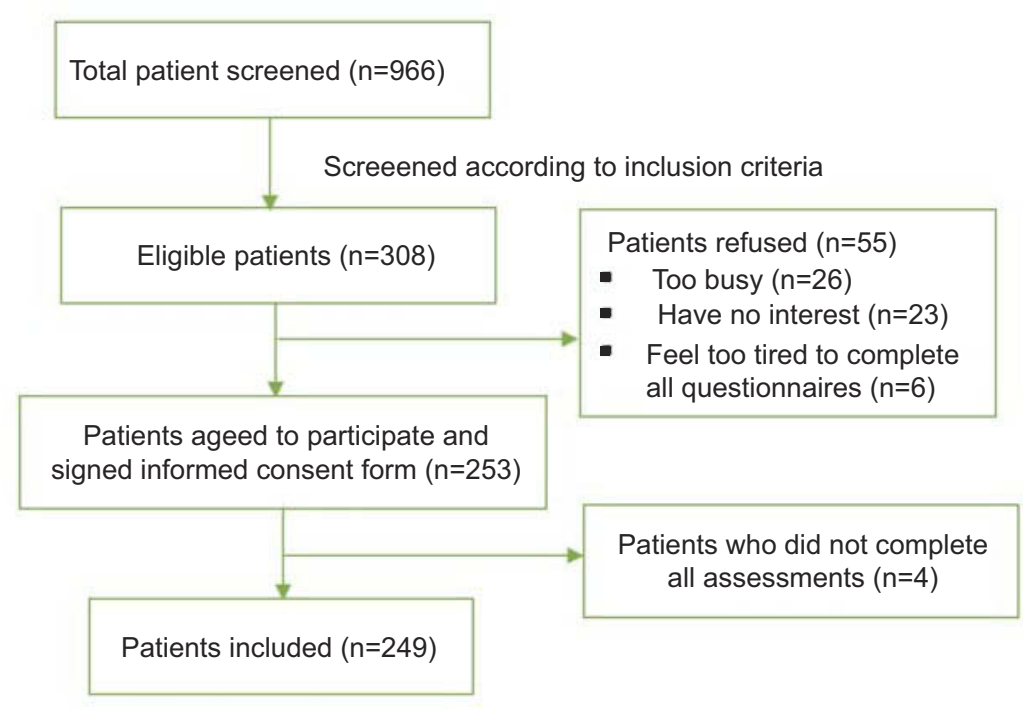

Figure I Recruitment flowchart. 
employment (59.8\%). More than half of the participants suffered from breast cancer (58.6\%), and had been through radiation treatment $(77.5 \%)$, chemotherapy $(82.7 \%)$ and/or surgery (87.6\%). Approximately $80 \%$ of them reported no family history of cancer or other physical comorbidities. More than $70 \%$ of the participants consider themselves as optimist and nearly $85 \%$ of them are facing at least one stressful live event. Only $5.6 \%$ of the AYAs reported previous experience with adversity. In total, eighty-nine (35.74\%) patients experienced dysfunctional level of FCR, eighty-two (32.93\%) patients experienced anxiety symptoms and ninety-six (38.55\%) reported depressive symptoms. Table 1 displays the participants sociodemographic, clinical and psychological characteristics.

\section{Univariate and multivariate analyses}

Univariate analyses indicated that most of the sociodemographic or clinical factors were not related to patients' psychological distress. However, four variables, namely, marital status, physical comorbidity, personality and stressful life event(s), were found to be significantly associated with FCR, anxiety and depression level. Additionally, past experience with adversity was positively associated with FCR. Cancer site, stage, radiotherapy as well as family history was significantly associated with anxiety (see Table 1).

Score of anxiety and depression were found to be significantly correlated with each other $(\mathrm{r}=0.810, P<0.001)$ and with the score of FCR $(\mathrm{r}=0.308, P<0.001$, and $\mathrm{r}=0.357$, $P<0.001$, respectively). In multiple linear regression analyses, being single, pessimistic, having more concurrent stressful life events and physical comorbidity were confirmed to be independently associated with higher FCR, anxiety and depression level. Moreover, patients who were not engaging in radiation treatment were more likely to report higher anxiety level (see Table 2).

\section{Discussion}

\section{Prevalence}

To the authors' best knowledge, this is the first study in China to investigate the prevalence and correlates of FCR, anxiety and depressive symptoms in AYA cancer patients. Many studies have been conducted to provide overall knowledge about mood disturbances in adult cancer patients; however, very few have focused specifically on AYA population. In 2018, an epidemiological study on FCR in AYAs was published by Thewes and colleagues in the Netherlands. This study included 73 patients aged 18 to 35 years and found that $62 \%$ of the patients reported higher FCR. ${ }^{4}$ In the same year, Mattsson et al. investigated 337 AYA cancer patients and reported that about $61 \%$ of the participants experienced FCR, $53 \%$ of them experienced anxiety and $51 \%$ of them reported depression. ${ }^{34}$ A similar study was conducted by Cho et al. recently in the US and they found that approximately half of the AYAs reported moderate-to-high FCR, and around 13\% reported higher FCR. A newly published review by Yang et al. found that the prevalence of FCR ranged from $31 \%$ to 85.2\% in AYA cancer population, and psychological distress was positively associated with higher FCR. ${ }^{23}$

Compared to previous findings, ${ }^{4,34,35}$ the current study found a smaller proportion (35.74\%) of AYAs experienced dysfunctional level of FCR, anxiety (32.93\%) and depression $(38.55 \%)$.

The differences of results could be partially explained by the difference in the study population and patients' socio-cultural background. Also, a range of instruments was used across studies, and the number of scale items varied widely. Other reasons could be the lack of consensus in standard definition of clinical or dysfunctional FCR and insufficient efforts made to establish the same clinical cut-offs for FCR. Therefore, we suggest that these prevalence results be interpreted with caution. However, the findings of the current study did confirm that FCR, anxiety as well as depressive symptoms are common concerns among AYAs. One possible reason is that the AYAs view their cancer as more unexpected and overwhelming, and thus, experience more psychological maladaptation. ${ }^{11}$

\section{Correlates}

Our study found that marital status, personality, physical comorbidity and stressful life event(s) were significantly independently associated with FCR, anxiety and depression. This is consistent with several previous studies in adult cancer samples. Yang et al. found that single patients were more likely to report higher FCR than those who were married or had marriage history, ${ }^{12}$ and plenty of evidence revealed that stressful events predispose cancer patients to developing higher FCR, anxiety and depression. ${ }^{36-38}$ Studies also indicated that stress was the only significant factor that related to elevated FCR and lower psychological well-being among eight domains of life. ${ }^{38}$ Researchers believe that managing stressful life events may largely waste patients' mental energy and resources, which make them more vulnerable to mental disease $^{39}$ and poor quality of life, ${ }^{40}$ especially for those AYAs who underwent Hematopoietic Stem Cell Transplantation. 
Table I Univariate analyses of factors associated with fear of recurrence, depression and anxiety $(\mathrm{N}=249)$.

\begin{tabular}{|c|c|c|c|c|c|c|c|c|c|c|}
\hline & \multirow[b]{2}{*}{$\mathbf{N}(\%)$} & \multicolumn{3}{|c|}{ Fear of recurrence } & \multicolumn{3}{|c|}{ Depression } & \multicolumn{3}{|l|}{ Anxiety } \\
\hline & & $\begin{array}{l}\text { Mean } \\
\pm S D\end{array}$ & T/F & $\begin{array}{l}P \text { - } \\
\text { value }\end{array}$ & $\begin{array}{l}\text { Mean } \\
\pm S D\end{array}$ & $\mathbf{Z}^{\mathbf{a} / \mathbf{b}}$ & $\begin{array}{l}P \text { - } \\
\text { value }\end{array}$ & $\begin{array}{l}\text { Mean } \\
\pm S D\end{array}$ & $\mathbf{Z}^{\mathbf{a} / \mathbf{b}}$ & $\begin{array}{l}P \text { - } \\
\text { value }\end{array}$ \\
\hline $\begin{array}{l}\text { Sociodemographic } \\
\text { Gender } \\
\text { Male } \\
\text { Female }\end{array}$ & $\begin{array}{l}79(31.7) \\
170(68.3)\end{array}$ & $\begin{array}{l}31.73 \pm 7.30 \\
30.92 \pm 7.21\end{array}$ & 0.823 & 0.411 & $\begin{array}{l}5.75 \pm 5.17 \\
5.34 \pm 5.02\end{array}$ & -0.817 & $0.4 \mid 4$ & $\begin{array}{l}4.94 \pm 4.23 \\
4.05 \pm 4.11\end{array}$ & -1.899 & 0.058 \\
\hline $\begin{array}{l}\text { Marital Status } \\
\text { Single } \\
\text { Married } \\
\text { Divorced/widowed }\end{array}$ & $\begin{array}{l}56(22.5) \\
183(73.5) \\
10(4.0)\end{array}$ & $\begin{array}{l}33.41 \pm 7.85 \\
30.78 \pm 6.73 \\
26.00 \pm 9.17\end{array}$ & 5.718 & 0.004 & $\begin{array}{l}6.84 \pm 5.28 \\
5.19 \pm 5.01 \\
2.90 \pm 2.81\end{array}$ & 9.062 & 0.011 & $\begin{array}{l}5.93 \pm 4.58 \\
3.97 \pm 3.96 \\
1.90 \pm 2.47\end{array}$ & 15.156 & 0.001 \\
\hline $\begin{array}{l}\text { Education } \\
\text { High School or below } \\
\text { Undergraduate } \\
\text { Postgraduate }\end{array}$ & $\begin{array}{l}128(51.4) \\
93(37.3) \\
28(11.2)\end{array}$ & $\begin{array}{l}30.54 \pm 6.90 \\
31.54 \pm 6.98 \\
32.93 \pm 9.19\end{array}$ & 1.440 & 0.239 & $\begin{array}{l}5.77 \pm 5.80 \\
5.15 \pm 3.90 \\
5.18 \pm 4.97\end{array}$ & 0.374 & 0.829 & $\begin{array}{l}4.66 \pm 4.60 \\
4.04 \pm 3.45 \\
3.75 \pm 4.18\end{array}$ & 1.095 & 0.578 \\
\hline $\begin{array}{l}\text { Employment } \\
\text { Full time } \\
\text { Part time } \\
\text { Unemployment }\end{array}$ & $\begin{array}{l}149(59.8) \\
20(8.0) \\
80(32.1)\end{array}$ & $\begin{array}{l}31.10 \pm 7.02 \\
32.60 \pm 6.92 \\
30.98 \pm 7.73\end{array}$ & 0.425 & 0.654 & $\begin{array}{l}5.29 \pm 4.41 \\
5.80 \pm 4.40 \\
5.73 \pm 6.26\end{array}$ & 1.027 & 0.598 & $\begin{array}{l}4.17 \pm 3.85 \\
4.90 \pm 3.40 \\
4.48 \pm 4.86\end{array}$ & 1.728 & 0.421 \\
\hline $\begin{array}{l}\text { Clinical/treatment } \\
\text { Cancer site } \\
\text { Breast cancer } \\
\text { Leukemia } \\
\text { Colorectal cancer } \\
\text { Nasopharynx cancer }\end{array}$ & $\begin{array}{l}\text { I } 46(58.6) \\
7 \mid(28.5) \\
2 \text { I }(8.4) \\
\text { II }(4.4)\end{array}$ & $\begin{array}{l}30.68 \pm 7.28 \\
31.85 \pm 7.02 \\
32.19 \pm 6.33 \\
31.55 \pm 9.68\end{array}$ & 0.571 & 0.634 & $\begin{array}{l}5.18 \pm 4.94 \\
6.08 \pm 5.77 \\
5.19 \pm 4.26 \\
5.82 \pm 2.86\end{array}$ & 2.140 & 0.544 & $\begin{array}{l}3.86 \pm 4.08 \\
5.46 \pm 4.62 \\
3.14 \pm 2.43 \\
5.45 \pm 3.01\end{array}$ & 11.236 & 0.011 \\
\hline $\begin{array}{l}\text { Stage } \\
\text { Stage } 1 \\
\text { Stage } 2 \\
\text { Stage } 3 \\
\text { Stage } 4\end{array}$ & $\begin{array}{l}24(9.6) \\
115(46.2) \\
86(34.5) \\
24(9.6)\end{array}$ & $\begin{array}{l}28.46 \pm 7.20 \\
31.06 \pm 7.19 \\
31.86 \pm 6.55 \\
32.04 \pm 7.23\end{array}$ & $1.52 \mathrm{I}$ & 0.210 & $\begin{array}{l}4.29 \pm 3.65 \\
5.10 \pm 4.90 \\
5.74 \pm 5.21 \\
7.46 \pm 6.12\end{array}$ & 4.257 & 0.235 & $\begin{array}{l}3.38 \pm 2.93 \\
3.65 \pm 3.92 \\
4.97 \pm 4.16 \\
6.25 \pm 5.39\end{array}$ & 10.975 & 0.012 \\
\hline $\begin{array}{l}\text { Chemotherapy } \\
\text { Yes } \\
\text { No }\end{array}$ & $\begin{array}{l}206(82.7) \\
43(17.3)\end{array}$ & $\begin{array}{l}31.45 \pm 7.43 \\
29.88 \pm 6.08\end{array}$ & -1.295 & 0.197 & $\begin{array}{l}5.5 \mathrm{I} \pm 5.09 \\
5.26 \pm 4.96\end{array}$ & -0.112 & 0.911 & $\begin{array}{l}4.20 \pm 4.11 \\
4.95 \pm 4.36\end{array}$ & -1.409 & 0.159 \\
\hline $\begin{array}{l}\text { Radiotherapy } \\
\text { Yes } \\
\text { No }\end{array}$ & $\begin{array}{l}193(77.5) \\
56(22.5)\end{array}$ & $\begin{array}{l}31.37 \pm 7.00 \\
30.54 \pm 8.00\end{array}$ & -0.758 & 0.449 & $\begin{array}{l}5.22 \pm 4.94 \\
6.34 \pm 5.42\end{array}$ & -1.373 & 0.170 & $\begin{array}{l}3.91 \pm 3.96 \\
5.77 \pm 4.54\end{array}$ & -3.210 & 0.001 \\
\hline $\begin{array}{l}\text { Surgery history } \\
\text { Yes } \\
\text { No }\end{array}$ & $\begin{array}{l}218(87.6) \\
31(12.4)\end{array}$ & $\begin{array}{l}31.28 \pm 7.03 \\
30.45 \pm 8.62\end{array}$ & -0.599 & 0.550 & $\begin{array}{l}5.53 \pm 5.18 \\
5.06 \pm 4.18\end{array}$ & -0.149 & 0.882 & $\begin{array}{l}4.39 \pm 4.32 \\
3.94 \pm 2.79\end{array}$ & -0.171 & 0.865 \\
\hline $\begin{array}{l}\text { Family history } \\
\text { Yes } \\
\text { No }\end{array}$ & $\begin{array}{l}55(22.1) \\
194(77.9)\end{array}$ & $\begin{array}{l}31.80 \pm 6.91 \\
31.01 \pm 7.33\end{array}$ & -0.719 & 0.473 & $\begin{array}{l}6.07 \pm 5.06 \\
5.30 \pm 5.06\end{array}$ & -1.389 & 0.165 & $\begin{array}{l}5.53 \pm 4.55 \\
3.99 \pm 3.99\end{array}$ & -2.643 & 0.008 \\
\hline $\begin{array}{l}\text { Physical comorbidity } \\
\text { No } \\
\text { Yes }\end{array}$ & $\begin{array}{l}200(80.3) \\
49(19.7)\end{array}$ & $\begin{array}{l}30.53 \pm 7.16 \\
33.86 \pm 6.98\end{array}$ & 2.935 & 0.004 & $\begin{array}{l}4.85 \pm 4.39 \\
8.00 \pm 6.65\end{array}$ & $-2.95 I$ & 0.003 & $\begin{array}{l}3.78 \pm 3.56 \\
6.57 \pm 5.52\end{array}$ & -3.224 & 0.001 \\
\hline
\end{tabular}




\begin{tabular}{|c|c|c|c|c|c|c|c|c|c|c|}
\hline & \multirow[b]{2}{*}{$\mathbf{N}(\%)$} & \multicolumn{3}{|c|}{ Fear of recurrence } & \multicolumn{3}{|c|}{ Depression } & \multicolumn{3}{|l|}{ Anxiety } \\
\hline & & $\begin{array}{l}\text { Mean } \\
\pm S D\end{array}$ & $\mathbf{T} / \mathbf{F}$ & $\begin{array}{l}P \text { - } \\
\text { value }\end{array}$ & $\begin{array}{l}\text { Mean } \\
\pm S D\end{array}$ & $\mathbf{Z}^{\mathrm{a} / \mathrm{b}}$ & $\begin{array}{l}P \text { - } \\
\text { value }\end{array}$ & $\begin{array}{l}\text { Mean } \\
\pm S D\end{array}$ & $\mathbf{Z}^{\mathrm{a} / \mathbf{b}}$ & $\begin{array}{l}P \text { - } \\
\text { value }\end{array}$ \\
\hline $\begin{array}{l}\text { Psychological } \\
\text { Personality } \\
\text { Positive } \\
\text { Negative }\end{array}$ & $\begin{array}{l}\text { I78 (7I.5) } \\
7 \mid(28.5)\end{array}$ & $\begin{array}{l}30.07 \pm 7.09 \\
33.97 \pm 6.86\end{array}$ & -3.959 & $<0.001$ & $\begin{array}{l}4.51 \pm 4.14 \\
7.87 \pm 6.28\end{array}$ & -4.259 & $<0.001$ & $\begin{array}{l}3.67 \pm 3.45 \\
5.97 \pm 5.23\end{array}$ & -3.279 & 0.001 \\
\hline $\begin{array}{l}\text { Stressful life event(s) } \\
\text { None } \\
\text { Less than } 3 \\
3-5 \\
\text { More than } 5\end{array}$ & $\begin{array}{l}44(17.7) \\
117(47.0) \\
66(26.5) \\
22(8.8)\end{array}$ & $\begin{array}{l}26.89 \pm 6.35 \\
31.09 \pm 6.66 \\
32.06 \pm 7.31 \\
37.59 \pm 6.40\end{array}$ & 12.888 & $<0.001$ & $\begin{array}{l}3.05 \pm 3.52 \\
4.57 \pm 3.71 \\
7.36 \pm 6.07 \\
9.41 \pm 6.57\end{array}$ & 32.611 & $<0.00$ I & $\begin{array}{l}2.43 \pm 3.30 \\
3.90 \pm 3.04 \\
5.61 \pm 5.44 \\
6.59 \pm 4.49\end{array}$ & 22.701 & $<0.001$ \\
\hline $\begin{array}{l}\text { Past adversity } \\
\text { experience } \\
\text { Yes } \\
\text { No }\end{array}$ & $\begin{array}{l}14(5.6) \\
235(94.4)\end{array}$ & $\begin{array}{l}33.57 \pm 3.99 \\
31.04 \pm 7.36\end{array}$ & -2.164 & 0.044 & $\begin{array}{l}8.21 \pm 6.46 \\
5.31 \pm 4.94\end{array}$ & -1.857 & 0.063 & $\begin{array}{l}5.7 I \pm 5.8 I \\
4.25 \pm 4.04\end{array}$ & -0.786 & 0.432 \\
\hline
\end{tabular}

Notes: ${ }^{a}$ Mann-Whitney $U$ test; ${ }^{b}$ Kruskal-Wallis test; bold $=P<0.05$.

Table 2 Multiple linear regression for fear of recurrence, depression and anxiety $(\mathrm{N}=249)$.

\begin{tabular}{|c|c|c|c|c|c|c|}
\hline & $\boldsymbol{\beta}$ & $\mathbf{t}$ & $P$-value & $\mathbf{R}^{2}$ & Adj. $\mathbf{R}^{2}$ & F ( $P$-value $)$ \\
\hline \multicolumn{7}{|l|}{ Fear of recurrence } \\
\hline Constant & - & 13.358 & $<0.001$ & & & \\
\hline Adversity experience & 0.044 & 0.761 & 0.447 & & & \\
\hline Personality & 0.168 & 2.835 & 0.005 & & & \\
\hline Marital status & -0.253 & -4.387 & $<0.001$ & & & \\
\hline Number of stressful life event & 0.305 & 5.101 & $<0.001$ & & & \\
\hline Physical comorbidity & -0.135 & -2.373 & 0.018 & 0.226 & 0.211 & $|4.23|(<0.001)$ \\
\hline \multicolumn{7}{|l|}{ Depression } \\
\hline Constant & - & 2.999 & 0.003 & & & \\
\hline Personality & 0.213 & 3.702 & $<0.001$ & & & \\
\hline Marital status & -0.232 & -4.209 & $<0.001$ & & & \\
\hline Number of stressful life event & 0.313 & 5.414 & $<0.001$ & & & \\
\hline Physical comorbidity & -0.194 & -3.505 & 0.001 & 0.270 & 0.258 & $22.531(<0.001)$ \\
\hline \multicolumn{7}{|l|}{ Anxiety } \\
\hline Constant & - & 2.725 & 0.007 & & & \\
\hline Personality & 0.202 & 3.477 & 0.001 & & & \\
\hline Marital status & -0.206 & -3.480 & 0.001 & & & \\
\hline Number of stressful life event & 0.302 & 5.107 & $<0.001$ & & & \\
\hline Physical comorbidity & -0.193 & -3.438 & 0.001 & & & \\
\hline Radiotherapy & -0.211 & -3.274 & 0.001 & & & \\
\hline Cancer site & -0.080 & -1.379 & 0.169 & & & \\
\hline Cancer stage & 0.082 & $1.4 \mathrm{II}$ & 0.159 & & & \\
\hline Family cancer history & 0.035 & 0.616 & 0.538 & 0.297 & 0.273 & $12.650(<0.001)$ \\
\hline
\end{tabular}

Notes: Adj. $R^{2}=$ adjusted $R$ square; bold $=P<0.05$.

Patients with positive personality tend to have better psychological adjustment and psychosocial well-being. ${ }^{41,42}$ Previous studies also indicated that the level of optimism was negatively correlated with psychological distress, such as FCR, ${ }^{43}$ confirming that self-esteem is crucial in AYA cancer patients. ${ }^{44}$ Personality has been commonly viewed as an 
independent predictor of patient's psychological quality of life, ${ }^{45}$ and it is reasonable to assume that patients with optimistic personality are able to develop better mental resilience to cope with their difficulties, and therefore experience fewer disease-related mood disturbances. In accordance with previous findings, patients with more physical comorbidity reported elevated fear, anxiety and depression. ${ }^{11,46}$ It has been consistently identified that physical as well as cognitive impairments via physical symptoms/treatment complications could lead to more psychological difficulties. ${ }^{25}$ One possible reason is that patients considered their symptoms/comorbidities as a sign of getting a more progressive disease and misinterpreted their symptoms as an alarm signal of cancer recurrence. ${ }^{14}$

Additionally, our study found that radiation treatment was independently associated with patients' anxiety level. However, inconsistent results were reported regarding the role of treatment type, and the relationship between radiotherapy and anxiety has not been clear. Previous studies indicated either treatment modality or intensity influenced a patient's anxiety level. ${ }^{47,48}$ More studies should be conducted to investigate the association between treatment type and anxiety in detail. Contrarily, previous studies found that having a family cancer history was not only significantly related to elevated FCR, but also positively associated with anxiety, somatization, avoidance, depression and intrusive thoughts. ${ }^{49-51}$ However, in the current study, no association between family history and psychological disturbances was found.

There are several limitations to this study. First of all, this was a cross-sectional study which could not draw any causal association between tested variables and target dependent variables. Longitudinal studies are needed to further identify the causal association. Second, the sample size of this study was limited and only AYAs in two hospitals were involved. Sample bias may exist as nearly $70 \%$ of the participants were female. Thus, the results should be interpreted with caution and cannot be generalized to the entire Chinese AYA cancer patients. Third, all results were based on self-reported data, and some characteristics were assessed using self-designed single question. Recall bias may exist, and the self-designed questions failed to provide solid psychometric information. A further multicenter large-sample investigation using validated objective instruments is warranted. Finally, other crucial characteristics of AYA cancer patients, such as time since diagnosis, perceived family support and socioeconomic status were not assessed in the current study. Further studies are needed to examine the influence of these variables in detail.

\section{Conclusion}

Unexpected cancer diagnosis and treatment may present great challenges to AYA population as it may affect their future choices in education, intimate relationships and occupational pursuits. However, very few studies have concentrated specifically on mood disturbances of AYA cancer population. This study found that FCR, anxiety and depressive symptoms are common concerns among Chinese AYA cancer patients. It is of importance to develop detailed guidelines and age-appropriate and flexible psychological interventions for this special group of people. Consequently, a multidisciplinary team would help early identification, intervention, management and provide the unique needs of AYAs.

\section{Ethics approval}

The Southern Medical University Nanfang Hospital and Guangdong Provincial People's Hospital Research Ethics Committee examined and approved the study (ref No: NFEC-2018-038, and 2018295H(R1)).

\section{Acknowledgments}

We would like to thank all participants and all colleagues who we have discussed this manuscript with. This study is funded by the Guangzhou Science and Technology Project (201804010132), the Science and Technology Project of Guangdong Province (2015A030302025); and the President Foundation of Nanfang Hospital, Southern Medical University (2017L001).

\section{Disclosure}

The authors report no conflicts of interest in this work.

\section{References}

1. Shay LA, Carpentier MY, Vernon SW. Prevalence and correlates of fear of recurrence among adolescent and young adult versus older adult post-treatment cancer survivors. Support Care Cancer. 2016;24 (11):4689-4696. doi:10.1007/s00520-016-3317-9

2. NIH. National Cancer Institute: adolescents and young adults with cancer. 2018 [cited September 20, 2018]. Available from: https://www. cancer.gov/types/aya.

3. WHO. Adolescent health. 2018 [cited January 20, 2019]. Available from: https://www.who.int/topics/adolescent_health/en/.

4. Thewes B, Kaal SEJ, Custers JAE, et al. Prevalence and correlates of high fear of cancer recurrence in late adolescents and young adults consulting a specialist adolescent and young adult (AYA) cancer service. Support Care Cancer. 2018;26(5):1479-1487. doi:10.1007/ s00520-017-3975-2 
5. Hartl K, Janni W, Kästner R, et al. Impact of medical and demographic factors on long-term quality of life and body image of breast cancer patients. Ann Oncol. 2003;14(7):1064-1071.

6. Hodgkinson K, Butow P, Hunt GE, et al. The development and evaluation of a measure to assess cancer survivors' unmet supportive care needs: the CaSUN (Cancer Survivors' Unmet Needs measure). Psychooncology. 2007;16(9):796-804. doi:10.1002/pon.1137

7. Hodgkinson K, Butow P, Hunt GE, Pendlebury S, Hobbs KM, Wain G. Breast cancer survivors' supportive care needs $2-10$ years after diagnosis. Support Care Cancer. 2007;15(5):515-523. doi:10.1007/s00520-006-0170-2

8. Lebel S, Ozakinci G, Humphris G, et al. From normal response to clinical problem: definition and clinical features of fear of cancer recurrence. Support Care Cancer. 2016;24(8):3265-3268. doi:10.1007/s00520-016-3272-5

9. Herschbach P, Dinkel A. Fear of progression. Recent Results Cancer Res. 2014;197(1):11-29. doi:10.1007/978-3-642-4018792

10. Custers JA, van den Berg SW, van Laarhoven HWM, Bleiker EMA, Gielissen MFM, Prins JB. The cancer worry scale: detecting fear of recurrence in breast cancer survivors. Cancer Nurs. 2014;37(1):E44 E50. doi:10.1097/NCC.0b013e3182813a17

11. Simard S, Thewes B, Humphris G, et al. Fear of cancer recurrence in adult cancer survivors: a systematic review of quantitative studies. J Cancer Surviv. 2013;7(3):300-322. doi:10.1007/s11764-013-0272-z

12. Yang Y, Sun H, Liu T, et al. Factors associated with fear of progression in chinese cancer patients: sociodemographic, clinical and psychological variables. $J$ Psychosom Res. 2018;114:18-24. doi:10.1016/j.jpsychores.2018.09.003

13. Koch L, Jansen L, Brenner H, Arndt V. Fear of recurrence and disease progression in long-term ( $\geq 5$ years) cancer survivors a systematic review of quantitative studies. Psychooncology. 2013;22(1):1-11. doi:10.1002/pon.3022

14. Yang Y, Cameron J, Humphris G. The relationship between cancer patient's fear of recurrence and radiotherapy: a systematic review and meta-analysis. Psychooncology. 2017;26(6):738-746. doi:10.1002/ pon. 4224

15. Yang Y, Wen Y, Bedi C, Humphris G. The relationship between cancer patient's fear of recurrence and chemotherapy: a systematic review and meta-analysis. J Psychosom Res. 2017;98:55-63. doi:10.1016/j.jpsychores.2017.05.002

16. Bultz BD, Carlson LE. Emotional distress: the sixth vital sign future directions in cancer care. Psychooncology. 2006;15(2):93-95. doi:10.1002/pon. 1022

17. DiMatteo MR, Lepper HS, Croghan TW. Depression is a risk factor for noncompliance with medical treatment: meta-analysis of the effects of anxiety and depression on patient adherence. Arch Intern Med. 2000;160(14):2101-2107.

18. Greer JA, Pirl WF, Park ER, Lynch TJ, Temel JS. Behavioral and psychological predictors of chemotherapy adherence in patients with advanced non-small cell lung cancer. J Psychosom Res. 2008;65 (6):549-552. doi:10.1016/j.jpsychores.2008.03.005

19. Pinquart M, Duberstein PR. Depression and cancer mortality: a meta-analysis. Psychol Med. 2010;40(11):1797-1810. doi:10.1017/ S0033291709992285

20. Singer S, Das-Munshi J, Brahler E. Prevalence of mental health conditions in cancer patients in acute care - a meta-analysis. Ann Oncol. 2010;21(5):925-930. doi:10.1093/annonc/mdp515

21. Linden W, Vodermaier A, Mackenzie R, Greig D. Anxiety and depression after cancer diagnosis: prevalence rates by cancer type, gender, and age. $J$ Affect Disord. 2012;141(2-3):343-351. doi:10.1016/j.jad.2012.03.025

22. Lang MJ, David V, Giese-Davis J. The age conundrum: a scoping review of younger age or adolescent and young adult as a risk factor for clinical distress, depression, or anxiety in cancer. J Adolesc Young Adult Oncol. 2015;4(4):157-173. doi:10.1089/jayao.2015.0005
23. Yang Y, Li W, Wen Y, et al. Fear of cancer recurrence in adolescent and young adult cancer survivors: a systematic review of the literature. Psychooncology. 2019. doi:10.1002/pon.5013

24. Yan S. The factorial structure study of the positive personality traits questionnaire. J Tangshan Teach Coll. 2013;3(1):140-143. Chinese.

25. Mehnert A, Berg P, Henrich G, Herschbach P. Fear of cancer progression and cancer-related intrusive cognitions in breast cancer survivors. Psychooncology. 2009;18(12):1273-1280. doi:10.1002/pon.1481

26. Mehnert A, Herschbach P, Berg P, Henrich G, Koch U. Fear of progression in breast cancer patients - validation of the short form of the Fear of Progression Questionnaire (FoP-Q-SF). Z Psychosom Med Psychother. 2006;52(3):274-288.

27. Melchior H, Büscher C, Thorenz A, Grochocka A, Koch U, Watzke B. Self-efficacy and fear of cancer progression during the year following diagnosis of breast cancer. Psychooncology. 2013;22(1):39-45. doi:10.1002/pon.2054

28. Wu Q, Ye Z, Li L, Liu P. Reliability and validity of Chinese version of Fear of Progression Questionnaire-Short Form for cancer patients. Chin J Nurs. 2015;12(12):1515-1519. Chinese.

29. Herschbach P, Berg P, Waadt S, et al. Group psychotherapy of dysfunctional fear of progression in patients with chronic arthritis or cancer. Psychother Psychosom. 2010;79(1):31-38. doi:10.1159/000254903

30. Spitzer RL, Kroenke K, Williams JBW, Löwe B. A brief measure for assessing generalized anxiety disorder: the GAD-7. Arch Intern Med. 2006;166(10):1092-1097. doi:10.1001/archinte.166.10.1092

31. Zheng Q. Reliability and validity of Chinese version of Generalized Anxiety Disorder 7-item (GAD-7) scale in screening anxiety disorder in outpatients from traditional Chinese internal department. Chinese Mental Health. 2013;27(3):163-168. Chinese.

32. Kroenke K, Spitzer RL, Williams JBW, Löwe B. The patient health questionnaire somatic, anxiety, and depressive symptom scales: a systematic review. Gen Hosp Psychiatry. 2010;32(4):345-359. doi:10.1016/j.genhosppsych.2010.03.006

33. Chen M, Sheng L, Qu S. Diagnostic test of screening depressive disorder in general hospital with the Patient Health Questionnaire. Chinese Mental Health. 2015;29(4):241-245. Chinese.

34. Mattsson E, Einhorn K, Ljungman L, Sundström-Poromaa I, Stålberg K, Wikman A. Women treated for gynaecological cancer during young adulthood - a mixed-methods study of perceived psychological distress and experiences of support from health care following end-of-treatment. Gynecol Oncol. 2018;149(3):464-469. doi:10.1016/j.ygyno.2018.03.055

35. Cho D, Park CL. Moderating effects of perceived growth on the association between fear of cancer recurrence and health-related quality of life among adolescent and young adult cancer survivors. $J$ Psychosoc Oncol. 2017;35(2):148-165. doi:10.1080/ 07347332.2016.1247408

36. Burgess C, Cornelius V, Love S, Graham J, Richards M, Ramirez A. Depression and anxiety in women with early breast cancer: five year observational cohort study. BMJ. 2005;330(7493):702-704. doi:10.1136/bmj.38343.670868.D3

37. Green BL, Krupnick JL, Rowland JH, et al. Trauma history as a predictor of psychologic symptoms in women with breast cancer. J Clin Oncol. 2000;18(5):1084-1093. doi:10.1200/JCO.2000.18.5.1084

38. Thewes B, Bell ML, Butow P, et al. Psychological morbidity and stress but not social factors influence level of fear of cancer recurrence in young women with early breast cancer: results of a cross-sectional study. Psychooncology. 2013;22(12):2797-2806. doi:10.1002/pon.3348

39. Mellon S, Kershaw TS, Northouse LL, Freeman-Gibb L. A family-based model to predict fear of recurrence for cancer survivors and their caregivers. Psychooncology. 2007;16(3):214-223. doi:10.1002/pon.1074

40. Reinfjell T, Tremolada M, Zeltzer LK. A review of demographic, medical, and treatment variables associated with Health-Related Quality of Life (HRQOL) in survivors of Hematopoietic Stem Cell (HSCT) and Bone Marrow Transplantation (BMT) during childhood. Front Psychol. 2017;8:253. doi:10.3389/fpsyg.2017.00253 
41. Carver CS, Pozo C, Harris SD, et al. How coping mediates the effect of optimism on distress: a study of women with early stage breast cancer. J Pers Soc Psychol. 1993;65(2):375-390.

42. Carver CS, Pozo-Kaderman C, Harris SD, et al. Optimism versus pessimism predicts the quality of women's adjustment to early stage breast cancer. Cancer. 1994;73(4):1213-1220.

43. Dumalaon-Canaria JA, Prichard I, Hutchinson AD, Wilson C. Fear of cancer recurrence and psychological well-being in women with breast cancer: the role of causal cancer attributions and optimism. Eur J Cancer Care (Engl). 2018;27(1):1-12. doi:10.1111/ecc.2018.27.issue-1

44. Tremolada M, Taverna L, Bonichini S, Basso G, Pillon M. Selfesteem and academic difficulties in preadolescents and adolescents healed from paediatric leukaemia. Cancers (Basel). 2017;9 (12):55-68. doi:10.3390/cancers9060055

45. Deimling GT, Bowman KF, Sterns S, Wagner LJ, Kahana B. Cancerrelated health worries and psychological distress among older adult, long-term cancer survivors. Psychooncology. 2006;15(4):306-320. doi:10.1002/pon.955

46. Braamse AM, van Turenhout ST, Terhaar Sive Droste JS, et al. Factors associated with anxiety and depressive symptoms in colorectal cancer survivors. Eur J Gastroenterol Hepatol. 2016;28 (7):831-835. doi:10.1097/MEG.0000000000000615
47. Inhestern L, Beierlein V, Bultmann JC, et al. Anxiety and depression in working-age cancer survivors: a register-based study. BMC Cancer. 2017;17(1):347-355. doi:10.1186/s12885-0173347-9

48. Kiefer T, Krahl D, Hirt C, Völler H, Völkel L, Daeschlein G. Influence of treatment caused impairments on anxiety and depression in patients with cancer of the esophagus or the esophagogastric junction. J Gastrointest Cancer. 2019. doi:10.1007/s12029-01800193-7

49. Horowitz M, Wilner N, Alvarez W. Impact of event scale: a measure of subjective stress. Psychosom Med. 1979;41(3):209-218.

50. Kash KM, Holland JC, Halper MS, Miller DG. Psychological distress and surveillance behaviors of women with a family history of breast cancer. J Natl Cancer Inst. 1992;84 (1):24-30.

51. Lerman C, Daly M, Sands C, et al. Mammography adherence and psychological distress among women at risk for breast cancer. J Natl Cancer Inst. 1993;85(13):1074-1080.

\section{Publish your work in this journal}

Neuropsychiatric Disease and Treatment is an international, peerreviewed journal of clinical therapeutics and pharmacology focusing on concise rapid reporting of clinical or pre-clinical studies on a range of neuropsychiatric and neurological disorders. This journal is indexed on PubMed Central, the 'PsycINFO' database and CAS, and is the official journal of The International Neuropsychiatric Association (INA). The manuscript management system is completely online and includes a very quick and fair peer-review system, which is all easy to use. Visit http://www.dovepress.com/testimonials.php to read real quotes from published authors. 